\title{
Socio-cultural factors influencing the prevalence, care and support in HIV/AIDS among the Yoruba of Southwestern Nigeria
}

\author{
Ajala Aderemi Suleiman \\ Department of Archaeology and Anthropology University of Ibadan, Ibadan. Nigeria. \\ asajala@yahoo.co.uk
}

\begin{abstract}
SUMMARY
This paper is a part of a bigger ethnographic study conducted in two states from the Yoruba society of the Southwestern Nigeria to examine the social and cultural factors influencing the prevalence of HIV/AIDS and care and support systems in those states. This is in recognition of the need to arrest the increasing rate of the spread of the epidemic and the desire to create better care for People Living with HIV/AIDS (PLWAs) in those states. The study employed both qualitative and quantitative methods using key-informant interviews, in-depth interviews, focus group discussions and case-study analyses. The study engaged in intensive fieldwork, which lasted for $\mathbf{2 4}$ months. The study examined in historical perspective, the condition of health facilities in the study area before the outbreak of HIV/AIDS and how such facilities have coped with HIV/AIDS. The study revealed that the socio-cultural condition of the society is not conducive to fighting HIV/AIDS. Poverty, low literacy capacity, the urbanization process, inadequate health care facilities, the location of tertiary institutions, and certain contesting issues in HIV/AIDS were found to account for the continued prevalence of HIV/AIDS in the study-area. In addition to the above, is the neglect of rural communities in HIV/AIDS programmes, despite the fact that PLWAs often return to their rural communities after contracting HIV/AIDS in their urban residence. HIV/AIDS is seen as a disease associated with human development, hence, action against the disease should involve the overhauling of the entire development process in the community studied.
\end{abstract}

\section{Introduction}

In the history of mankind, no other tragedy has ravaged both capital and human resources as much as HIV/AIDS. It is no wonder that the disease has drawn global attention. In many sub-Sahara African societies, the disease emerged at a time when there were general poor conditions of living such as high poverty rate, squalor, hunger, and unemployment. HIV/AIDS thus continues to thrive on these poor conditions [1]. The region is therefore ill equipped to respond to the scourge of HIV/AIDS, hence the continuous growth of HIV/AIDS prevalence in the region.

In Nigeria, there exists political instability, ethnic crises, social decadence, urban migration, unemployment, poor and inadequate infrastructural facilities, widespread poverty and irregular academic sessions in all tiers of the educational system. The above problems contribute greatly to HIV/AIDS vulnerability and prevalence. The available data on HIV/AIDS prevalence revealed an increase from $1.8 \%$ in 1992 to $5.0 \%$ in 2003 [2, 3]. In 1999, there were 2.5 million AIDS infections in Nigeria, which were projected to rise to 3.8 million by 2005 [4]. At present, despite various strategies mounted against HIV/AIDS in Nigeria, the projection of 3.8 million infections has been met. In the Yoruba society of Nigeria comprising Oyo, Osun, Ogun, Ondo, Lagos and Ekiti States, there is no State that has less than $4.6 \%$ prevalence of HIV/AIDS. On the average, Yoruba society has $4.8 \%$ prevalence of HIV/AIDS as at 2005. While the statistics on HIV/AIDS continues to rise, the effect of the disease on families is increasingly being noticed. Many households have lost their able-bodied men and women to AIDS. That has also led to a serious decline in community's productivity. A lot of the public spending, which are supposed to have been expended on other development projects are channeled towards the prevention of HIV/AIDS and care [5]. Despite all these severities associated with HIV/AIDS in Nigeria, government actions are still directed at decision formulation level, which are yet to be translated into meaningful actions against the tides of the disease.

The above imply that within the first three decades of the emergence of HIV/AIDS, it remains a tragedy, affecting the social, political, economic, and biological existence of the ravaged communities. Therefore, the following questions arise: What is wrong with the conception of health in relation to HIV/AIDS? Why have the strategies initiated against HIV/AIDS failed? Are there any grounds yet to cover in researches on HIV/AIDS? 
Are the existing research findings capable of being translated into effective and positive actions against HIV/AIDS in the Yoruba community of Nigeria?

In an attempt to answer the above questions, a review of the existing research findings was done. The obvious gaps found include the absence of enough ideas that are culture-centered on HIV/AIDS. Most of the existing information on HIV/AIDS is generalized in the global context. Most of it has ignored the perception of local culture in explaining HIV/AIDS [6]. Another gap is poor harmonization of research findings from different disciplines, which could have generated ideas and knowledge leading to positive and pragmatic intervention against HIV/AIDS. This gap suggests that enough multi-disciplinary research on HIV/AIDS has not been conducted

The African conception of health assumes a holistic perception, which asserts that the state of health includes political, social, economic and "religious" well-being of individuals and communities. It suggests that health is a general well-being. HIV/AIDS has impact not only on the biological well-being, but also on the general wellbeing of individuals and that of the community. As declared by Kofi Annan [7], "AIDS is a threat to economic, social and political stability". This therefore justifies the desirability of examining the social and cultural factors of HIV/AIDS, with a view to understanding all the variables responsible for its prevalence and spread. Such an understanding would also generate actions for HIV/AIDS prevention and positive care and support for People Living with HIV/AIDS (PLWAs) in Yoruba communities.

The thrust of the argument in this study is the dependency theory, derived from the politicaleconomic thesis discussed by Ake [8]. Mufune [9] however, uses the theory to explain the nature of HIV/AIDS, in terms of global economic inequalities and political uncertainties. This perspective was initially discussed by Schoepf [10] who argued that the prevalence of HIV is determined by the international political economy, social structures and by the actions of individuals and groups, which are variously contained within the historically constructed system. Hunt [11], using Dependency and World Systems theory, demonstrated the geographic spread of the infection. He noted that the cities where manufacturing, schooling, and other commercial activities are concentrated have attracted people to seek employment from rural areas, which are crippled by poverty and are also neglected in development policies. Hunt [11] hypothesized that the pattern of HIV/AIDS spread was as a result of migrants moving into towns without wives. Since sexuality is an inherent nature of human beings [12], sometimes in many human societies sexuality is conducted without regards to sexual regulations in the society. The practice sometimes may breed negative sex behaviors, which may in turn lead to sexually- transmitted diseases. The migrants in the cities are usually vulnerable to such practices due to the inability of many traditional sexual regulatory norms to control illicit sexual behaviors in the cities. When the city migrants are infected with sexually transmitted diseases, especially HIV/AIDS in Nigeria they often go back to their rural areas where they further spread the disease. This position is in contrast to that of Caldwell et. al. [13] who emphasize the cultural explanation of HIV/AIDS. Cultural perspective looks at the behaviours and attitudes, which generate practices that could lead to infection of HIV/AIDS rather than both the institutions, and behaviours, which the dependency theory examines.

Arising from the above is that HIV infections are common in places with concentrations of migrant labour. This also explains why HIV/AIDS prevalence is high in Lesotho, where migrant labour is predominantly practiced. This position was demonstrated in the studies of Philipson and Posner [14], where it was established that large cities and long-distance transport routes in Africa have higher prevalence of HIV/AIDS when compared with other settings in Europe and North America.

Poverty affects fertility and sexual activity [9]. African women bear the higher brunt of poverty because they have low access to capital $[1,5$, and 15]. In traditional economy, they do not have access to cattle and land, while in modern economy they are discouraged from higher education and the labour market. They also face unequal opportunities in access to household resources [16]. Consequently, women do not have access to the few available jobs and sufficient income- earning. Since women have to live, some women depend on marriage and sex to access resources. Among many young and unmarried women, sex is the instrument with which they get jobs, qualify for higher education and even fulfill their requirements for award of certificate, especially when they migrate to urban communities. Many men on the other hand feel that they have right to demand sex from women in return for providing means of livelihood for women [5]. Thus, the social structure of rural poverty is related to migration and urban problems, which induce sexually transmitted diseases [11]. Unemployment, poverty and underdevelopment of the populated rural areas seem to be one of the factors contributing to the prevalence of HIV/AIDS. Aggravating this situation in Nigeria is the continuous neglect of these rural areas in government policies and the inability of the Nigerian government to avert the crises of poverty and unemployment, thus forcing more sexually active and productive men and women to migrate to cities where there are concentrations of 
commercial activities. Evolving from the above is the desire to ethnographically explain social and cultural factors influencing the prevalence, care and support in HIV/AIDS among the Yoruba of Western Nigeria.

\section{Materials and Methods}

This is both a qualitative and quantitative study conducted in Oyo and Osun States in the Yoruba society of Western Nigeria, where six studycommunities were randomly selected. The six communities were Ibadan, Iseyin, and Kishi in Oyo State; and Ilesha, Ifewara and Ila-Orangun in Osun State. Kishi, Ifewara and Iseyin are rural communities, while Ibadan, Ila-Orangun and Ilesha are urban areas as indicated in figure 1. below.

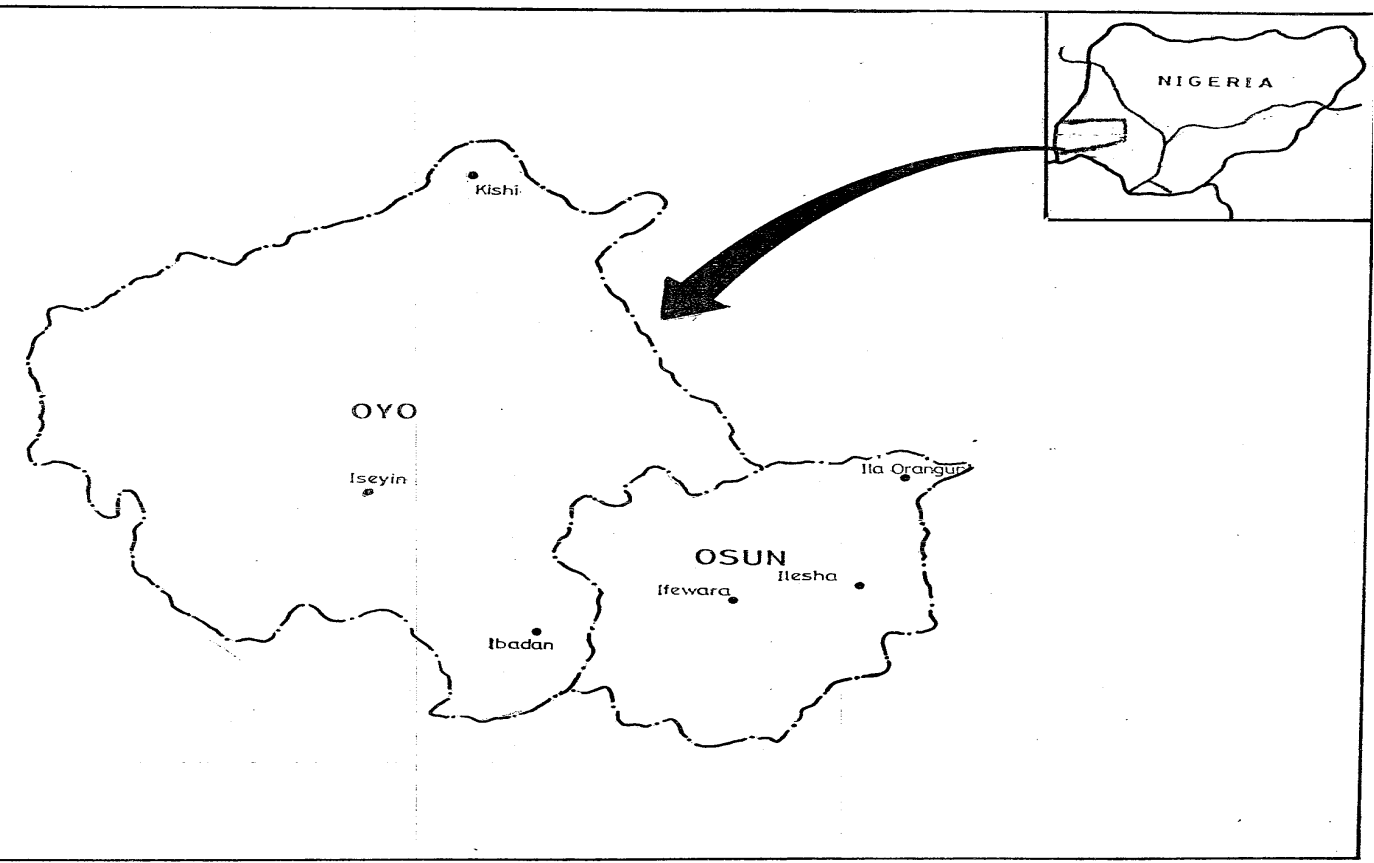

FIG. 1: MAP OF THE STUDY AREAS

The study is a multidisciplinary research on the broad theme "Cultural Context of HIV/AIDS in Yoruba Society". The study involved an Anthropologist as the principal investigator, a Sociologist, a Nurse and a Political Scientist as research assistants. The study involved 1023 respondents as the research elements. This large study element was motivated by the fact that the study was a long-term one, which lasted for four years of data collection. The entire research elements consisted of 423PLWAs as key informants and another 600 household respondents who were engaged in household survey. The 423 PLWA-Key informants were selected accidentally from among 1217 PLWAs found in hospitals and three NGOs (care centers) in Ilesa and Ibadan. Accidental sampling was used because PLWAS are not regular in the care centers. So it was difficult to use other types of sampling. Six hundred household respondents were selected randomly based on 100 respondents from each of the six communities studied.

Selection of household respondents was based on multi-random sampling system. This involved community-sampling, sampling of Enumeration Areas (EAs), household sampling and sampling of the respondents. Sampling of the respondents was based on $1 / 50^{\text {th }}$ sample frame of the entire population in each of the enumeration areas. The selection of the EAs was based on $1 / 10^{\text {th }}$ sample frame of the political wards in each of the communities sampled; another $1 / 5$ th sample frame was adopted for the selection of the households.

The respondents gave their consents, and were allowed to retract their information if they wished. The study also protected the respondents from physical harms. The administered questionnaires contained open-ended questions to allow secondorder questions being attended to. The questionnaires were semi-structured and the research assistants were the interviewers. Four hundred and twenty-three PLWAs selected as key informants were mainly selected from Ibadan and Ilesha being urban communities. It is only in the urban communities where groups of PLWAs with proof of the infections are found. They are mostly found in NGOs giving support and care for PLWAs and hospitals during medical care. The study 
recruited PLWAs from urban communities, because it is difficult to recruit PLWAs from the rural communities where there are no institutions giving care and support. In the rural communities, there is also secrecy on AIDS patients. They do not show up. Since AIDS manifest through opportunistic infections, it becomes difficult to identify AIDS patients in the rural areas, unless there is a medical evidence of positive status. The existence of institution caring and supporting PLWAs in the urban communities make it possible to locate PLWAs in the cities. Visitations were made to hospitals and Non-Governmental Organizations in Ibadan and Ilesha where care and support are provided for PLWAs.The PLWAs recruited from these institutions have both rural and urban background. Sixty-two percent $(62 \%)$ of them were infected in various cities in Nigeria, from where they came to seek for care and support in Ibadan and Ilesha. The remaining $32 \%$ of the sampled PLWAs was infected from the rural communities. The study also involved 24 different sessions of focus group discussions among the PLWAs and People Affected by AIDs (PABAs). FGD considers the social and demographic variables of the respondents, as well as their attitudes to care and support in the institutions caring for PLWAs.

Data analysis for this paper was mostly descriptive due to the nature of the available data (qualitative). The analytical component of data analysis is a summary of the data, which involves the following steps:

(i) Univariate analysis aimed at explaining the frequency distribution of the data, which include socio-demographic characteristics of the respondents.

(ii) Bivariate analysis conducted to examine simple associations between dependent and independent variables. The data were entered into thematic matrices, through which the configuration of common patterns and differences was done. Information reported are accompanied by quotes, which are the recorded explanations of the informants. The demographic data were analyzed and presented using frequency tables and simple percentages of some comparable data. The use of T-test was employed to deduct information from open-ended questions.

\section{Results}

This paper examines the socio -cultural nature of HIV/AIDS, and how it has influenced the prevalence HIV/AIDS, care and support in AIDS in the Yoruba society of western Nigeria. Thus, the analyzed data center on:

(i) Contesting issues in HIV/AIDS;

(ii) Poverty and HIV/AIDS;

(iii) Urbanization and HIV/AIDS;

(iv) HIV/AIDS and the educational system; (v) Government policies and HIV/AIDS and

(vi) Infrastructural facilities and HIV/AIDS.

\section{Contesting issues on HIV/AIDS}

It was discovered that there were five major contesting issues on HIV/AIDS among the studied population.

(1) The conception of HIV/AIDS. The Yoruba conception of HIV/AIDS is that the disease is a chronic Sexually Transmitted Disease (STD), which is related to gonorrhea. HIV/AIDS in some traditional communities is referred to as "ako atosi" (virulent gonorrhea). Sexually Transmitted Diseases are regarded as diseases caused by sexual immorality. Consequently, its victims cannot disclose as they would be treated with ridicule and embarrassed. The victims therefore only seek treatment secretly. Underlying that conception is the belief that HIV/AIDS is similarly a disease caused by immoral conduct, thus its victims should be made to serve the punishment for their indiscipline. This position is in contrast with western perceptions of HIV/AIDS. Because of these opposing views, many PLWAs do not have confidence in modern hospitals until the disease becomes advanced.

(2) The Yoruba people have the view that death would not occur without a cause, and that every human being has a destined cause of death. Among the Yoruba death as a result of HIV/AIDS infection is seen as the destiny of the victim. The people believe that if one is not destined to die through AIDS even if the person has contacts with an infected person, the person will not be infected. This belief makes many people (56\%)to feel nonchalant about unsafe sex. It also discourages the use of condom. Due to this belief, $53 \%$ of the respondents affirmed that they have not being using condom and they would not use it. According to a respondent:

No matter how one protects himself against AIDS, if it is destined one would die of AIDS, one cannot escape.

(3) Reactions to the campaign in favor of the use of condoms constitute another issue. People believe that using condoms is indirect sex, and it is not pleasurable and enjoyable, hence they are reluctant to use condoms. There is also a perception that the recommendation of condom has economic motives. It is believed that there are many traditional methods of contraceptives but they are not promoted simply because the foreign firms producing condoms are making huge sales. This belief discourages the use of condoms.

(4) The statistical prevalence of HIV/AIDS is also a contested issue among the Yoruba people, in that they believe it is grossly exaggerated. It is believed that HIV/AIDS is not as rampant as claimed; rather the claimed prevalence is economically and politically motivated. 
(5) The Yoruba people believe that HIV/AIDS is an incurable and fatal disease and that no amount of care given to PLWAs will avert death through AIDS. The knowledge of Anti Retro-viral drug is very low among the people. Even in the institutions caring for PLWAs, the use of ARVs is affected by some cultural factors. These include the side effect of the drugs. The PLWAs always complained that it makes them dizzy, and make them to loose their hair. ARVs are also affected by irregular supply to those who want to use the drug. There are also many PLWAs who could not afford the cost of ARVs. In the context of all the above the belief is that it is needless to care for the victims, because according to a respondent:

Caring for an HIV/AIDS patient is a sheer waste of both money and time.

\section{Influence of poverty on HIV/AIDS}

Sixty seven percent of the identified PLWAs are rural migrants to urban communities. Rural poverty drove them away from their rural communities to search for employment in urban areas. They migrated to the cities to secure a living. As there are no secured jobs in the cities, $92 \%$ of the migrants engage in menial jobs. Men have more access to menial jobs than women do, because there are more of such jobs, which the society ascribes to men than those available for women. Men engage in bus conducting, driving and various artisans upon migration to cities. This predisposes young women to engage in sex to augment their meager earnings, and sometimes as a means of livelihood pending when descent job would open for them. They eventually become commercial sex workers, a condition that makes them vulnerable to HIV/AIDS. Even men who engage in those menial and strenuous economic activities regard sex as a means of cooling down the stress from their menial engagements. This implies that as a result of women's inaccessibility to many jobs in the cities, they are more prone to some behaviors, which make them vulnerable to HIV/AIDS infection. Table 1 below shows women's occupation in the study area.

Table 1: Women's PLWAs Occupations in Yoruba urban communities

\begin{tabular}{|l|l|l|}
\hline Occupation & Frequency & \% \\
\hline Petty Trading & 58 & 17.5 \\
Artisanship & 53 & 16.0 \\
Unemployed & 101 & 30.0 \\
Professionals & 38 & 11.5 \\
Students & 85 & 25.0 \\
\hline Total & $\mathbf{3 3 0}$ & $\mathbf{1 0 0}$ \\
\hline
\end{tabular}

The above table shows that most PLWA women $(30 \%)$ were unemployed, while only $17.5 \%$ of them were engaged in petty trading such as caravan traders who travel to other places to buy items such as food materials and other domestic needs to be sold in the cities. Only $16 \%$ were engaged in artisanship such as hairdressing, tailoring and nylon cutting, while only $11.5 \%$ were professionals such as teachers, bankers, secretaries and broadcasters. The remaining $25 \%$ were students. The above implies that the infection of HIV/AIDS is more prevalent among the unemployed females and the students

Poverty also makes it difficult for the people to use condoms to protect themselves against the infection. As a result of poverty, when infected with sexually transmitted diseases they lack resources to visit clinics. In Nigeria, primary health care does not provide reproductive health care services freely. In addition, due to stigmatization, the victims of sexually transmitted diseases prefer treating their ailment secretly. They therefore depend on medical quacks and self-medication. A key informant (PLWA) reported as follows:

\section{Urbanization and HIV/AIDS}

Cities in the study area have many social institutions, which engage in different activities
When I got to Ibadan, I was learning hairdressing. But my sister I was living with did not give me transport money. A man used to give me a ride as well as some money. As a result, I kept him as my boyfriend. I soon noticed that he was getting leaner and leaner. Not long after this, he died. About six months after his death, I fell ill too, and returned to my hometown. I recovered and came back to Ibadan. But after three months, I broke down and was taken to UCH from where I was referred to this $N G O$ for care.

The above report vividly illustrates the pathetic influence of poverty on HIV/AIDS. Although this study did not measure poverty rate in the studied community, because poverty is a relative concept and it is difficult to measure to be able to generate uncontroversial and valid arguments, yet there are indications of household poverty in the communities. Most of the households (62.4\%) lack good nutritional culture, and they are not accessible to basic needs of life. Due to this household poverty, many people ignored basic health needs.

capable of spreading HIV/AIDS. These social institutions include hotels, brothels, fast food joints, big market places attractive to many people of 
diverse cultural backgrounds, and big motor parks, which are transit parks. Activities within these social locations encourage illicit sexuality. Most of these places in the cities are hives of itinerant commercial sex workers. In the rural areas, there are limited numbers of such social institutions. However, that does not suggest that itinerant sexuality is not conducted in the rural communities. It only means that opportunity for HIV/AIDS infection is lower in the rural areas compared to the cities. A respondent affirmed that:

This is a small town. We do not have hotels. Therefore, there is no place for our women to be involved in such an open prostitution. This assertion is further corroborated with another opinion from an urban key-informant, who claims that: Cities are not save. We do not know where each of us comes from, and neither do we know each person's health culture. Another problem with the cities is that many do not have job, and women are vulnerable to unregulated sexual conducts. Besides, there are many places in the cities where prostitutions are engaged. What I am saying is that Educational Institutions and HIV/AIDS.

Another characteristic of cities in the study area is the concentration of institutions of higher learning. In Ibadan alone, there is University of Ibadan, Ibadan Polytechnic and School of Nursing, which contain students (males and females) from different cultural backgrounds in Nigeria. Sixtyfive percent of the students in these schools are from rural areas. Many of the female students in these schools are exposed to city life, characterized by itinerant sexuality. They are engaged in this practice as a means to compliment their poor means of livelihood in schools. They are therefore attracted to unregulated sex, also, due to the collapse of sex morals. All these coupled with their diverse cultural backgrounds in terms of the cultural perception of sexuality, promotes their vulnerability to HIV/AIDS. This suggests that unregulated culture contact from different cultural groups may promote HIV transmission. However, this study was not meant to measure the link between urbanism, higher institutions and vulnerability to HIV/AIDS. It is discovered that as many people from different cultural background come into contact in social relationship, especially in societies where health education on HIV/AIDS is low, and the poverty rate is higher, there tends to be more vulnerability to HIV/AIDS infection among the people, more often through illicit sexuality. The situation in Osun State is worse. Within a distance of 100 kilometers, there are six higher educational institutions, four of which are non-residential. All these institutions have large numbers of students who are mostly from different rural areas in Nigeria. Due to poverty and women's unequal access to financial resources, many young women in these schools resort to sex as a means of accessing these resources. They are exposed in a similar manner to city-migrants. Thus, they are susceptible to HIV/AIDS infection.

Another related problem associated with the educational system in Nigeria is the irregular calendar and frequent strikes by teachers and lecturers, which make their students, idle whenever they are on strikes. Since they are sexually active, many of the young women among the students become itinerant commercial sex workers in cities when their schools are closed. This is to allow them to generate some cash for their studies. According to a PLWA in Ilesha: I think I contracted this disease in 1998. What happened then was that my school was closed due to the lecturers' strike then. When the school was closed, I went to stay with my friend in Ibadan. The two of us were engaged in sex business. Some years later, I discovered that I have been infected with HIV.

\section{Government policies and HIV/AIDS}

In the study-community, people are aware of some government policies on HIV/AIDS, including campaigns against HIV/AIDS. However, policy implementation is not effective in the rural communities due to rural poverty limiting access to media dissemination. Low literacy capacity also adversely affects dissemination of information. Similarly, many of the rural communities do not have regular supply of electricity, thus the dissemination of health information through electronic media is limited. Table 2 below shows the rural population access to electronic media in the study-area.

The rural communities also lack enough hospital facilities to cope with the problems of HIV/AIDS. Rural communities do not have enough health workers, and the few existing hospitals lack enough drugs and other amenities needed for health care. In the three rural communities selected for the study there were only three primary health centers. Each of them cannot cater for the health needs of more 75 persons at a time. All these communities have a population of 218,000 people according to the National Population figures released in 1991. Also the urban population is not adequately accessible to health care facilities. The cost of health care services also deprived many urban poor from health provisions.

In view of these problems, the data revealed that there is more prevalence of HIV/AIDS among the urban populations than the rural populations. For instance, in Ibadan city, the average prevalence of HIV/AIDS in 2004 was 3.6\%, while in Kishi, which is a rural community; the average is $1.2 \%$ [17]. Many factors are however provided for lowlevel prevalence of HIV/AIDS in rural communities in Nigeria. Among these is the poor medical record on diseases and illness due to overdependent on traditional health care system in rural 
communities. Also the culture of non-disclosure of HIV/AIDS status is still prevalent in rural communities than in urban communities in Nigeria. Nonetheless, it is evident that there are more cases of HIV/AIDS in urban communities due to the above-identified socio-cultural conditions, which make urban residents more vulnerable to HIV/AIDS.

Table 2: Household Access to Media Facilities in the Studied Rural Communities

\begin{tabular}{|l|l|l|}
\hline \multirow{2}{*}{ Media Facilities } & \multicolumn{2}{|l|}{ Household Access } \\
\cline { 2 - 3 } & Have (\%) & Don't have (\%) \\
\hline Radio & $23(7.6)$ & $277(92.4)$ \\
T.V. & $11(3.6)$ & $289(96.4)$ \\
Newspaper & $7(2.3)$ & $273(97.7)$ \\
Magazines & $5(1.6)$ & $295(98.4)$ \\
& & \\
\hline
\end{tabular}

\section{Discussion}

HIV/AIDS is a complex disease associated with social, political and economic disabilities of the societies affected [13, 18, 19]. It is not only a biological infection, but also political, social, economic and psychological. The pattern of spread, its prevalence, and the care and support in AIDS show that there are many interlocking variables contributing to the epidemic. These variables include gender inequity $[5,9]$, economic imbalance, and misplacement of priorities in government policies $[11,20]$. In addition, parts of the problems associated with the prevalence of HIV/AIDS in Yoruba society are the pattern and structure of urban communities, location of tertiary institutions in the society, contesting issues emanating from the people's perception of HIV/AIDS, and the breakdown of values attached to traditional socialization. All these factors are connected with the socio-cultural conditions of the society.

Unequal treatment given to women compared to men in the Yoruba society forms the basis of women being more vulnerable to HIV/AIDS than men are. The fact that women do not have equal access to society's resources such as capital, land and other social needs like their male counterparts exposes women to finding means of access to such resources. For many women, the available means is sexuality, which becomes an indiscriminate tool of access to resources. Such women are exposed to illicit pre-marital sexuality and after marriage they are exposed to extra-marital sex. While engaged in this practice, they are not usually mindful of the health conditions of their sex partners. Generally, among the Yoruba, and indeed in many subSaharan Africa, women are betrothed for marriage upon payment of marriage goods or dowry by their prospective husbands, thus selling out their sexual rights to men. Women then bequeath their sex rights to their husbands. Even if the husband is known to have health problems, in so far those problems have not impaired his manhood. Women do not have 'cultural' right to refuse sex. In many circumstances, the combined effect of the gender inequality is sexually related problems in women.

Presently prominent among these problems are sex violence and prostitution, which are capable of inducing HIV/AIDS. That explains why most women PLWAs are ignorant of how they were infected. They only have inferences of when the symptoms began to manifest. It also explains why the spread continues to grow especially among women.

Economic imbalances and misplacement of priorities in government policies serve as opportunities for the spread of HIV/AIDS. Economic imbalances existing between the rural and urban communities are the most common factors leading to the spread of HIV/AIDS in the Yoruba community. Due to the neglect of rural communities in terms of hospital facilities, higher education, good roads, communication, employment, and electricity, there is high urban migration. Unfortunately, the urban communities too, do not have enough social support systems to cope with the migrants. Thus, causing urban congestion and destitution. Women still become the brunt of these urban vices. This is because; there are certain menial jobs, which the society forbids women, thus limiting their chances of sustenance. Thus, many women resort to using sex to negotiate for their needs from men, not minding the health conditions of such men. Also emanating from society's economic imbalances is the problem of weak household economy to be able to fund the management of HIV/AIDS. Many households are financially weak to be able to fund the nutritional requirements of the epidemic much less the ability to procure the required drugs. This condition has created a serious and untold hardship on many PLWAs. Government, which supposes to avert the crisis, continues to focus on urban development. Many government offices, which are to create jobs, are situated in the urban communities still 
providing opportunities for rural-urban migration. Social amenities are located in the urban communities and such amenities provide more adequate services in their urban locations than when they are in rural communities.

Similarly, both the state and local governments do not accord good priority to the management of HIV/AIDS. In most of the states in the Yoruba community, government intervention against HIV/AIDS has political drives, which have marred the success of such intervention. In addition, corruption and poor knowledge of the government officers involved in the HIV/AIDS policy management frustrate the intervention approach.

Worsening the above socio-cultural conditions are certain contesting issues in HIV/AIDS. Many of these issues emanated from the Yoruba perception of HIV/AIDS. More prevalent among these contesting issues is the belief that HIV/AIDS is not manageable. This assumption originated from the earlier health education and knowledge about HIV/AIDS that the epidemic is incurable and deadly. This perception has caused fear on the management of HIV/AIDS rather than stopping illicit sexuality capable of spreading the HIV/AIDS. The epidemic is referred to as killer disease; implying that the infected person is already committed to death. This perception keeps the PLWAs away from care and support systems available for sick people in the Yoruba culture. Similarly, association of the disease with sexual immorality is another condemnation against positive and adequate care and support for PLWAs in the studied community.

The Yoruba belief in destiny constitutes another barrier against positive caring for PLWAs. Destiny is a predetermined cause, which cannot be changed. Death and its associated cause(s) are regarded as destiny, in which an individual destined to experience such has no power to change. Preoccupied with this belief, many people believe that it is the destiny of those infected with HIV/AIDS, and those that are not destined to be infected cannot be infected irrespective of their sexual immorality. This explains the people's reluctance to abstain from sex.

The reluctance to the use of condom is also supported by the perception that since World Health Organization (WHO) is busy promoting traditional methods of health caring, the organization is not fully in support of local contraceptives. The people believe that many of the local contraceptives are better than condom, but the local contraceptives are not promoted. The people believe that if there is need to protect illicit and unfaithful sex, why not use local contraceptives, which are affordable in cost, and accessibility. Undoubtedly, there seems to be no single remedy for solving the HIV/AIDS problem. Rather the whole cultural, social, and biological complexities capable of causing and promoting the epidemic need be known and acknowledged. In addition to the above, is the fact that HIV/AIDS is entirely depended on the political, social, economic, and even the religious factors in human societies. If these factors are understood, the prevalence of HIV/AIDS will be drastically reduced. However, of course, if there continue to be political uncertainties, economic inequalities, social decadence, and resilience of superstitious traditional beliefs, the prevalence of HIV/AIDS is bound to increase, and better care and support for PLWAs will be lacking.

From the existing literature on HIV/AIDS, it is clear that there are multiplicity of fragmented ideas and knowledge especially on HIV/AIDS in Nigeria. Such ideas and knowledge include virology of HIV/AIDS; epidemiology of HIV/AIDS; sociology of HIV/AIDS; legal issues on HIV/AIDS; sociopsychological insights on HIV/AIDS; economics of HIV/AIDS; HIV/AIDS and political decisions; Health education and information on HIV/AIDS; social medicine and HIV/AIDS and demographic insights on HIV/AIDS. It is however doubtful if these fragmented ideas and knowledge have been harmonized in such a way to have yielded a single body of knowledge capable of positive intervention against HIV/AIDS in Nigeria. Since modern knowledge exists on interconnectivity, for a meaningful intervention and change of attitudes on HIV/AIDS, there is need for harmonization of various knowledge on HIV/AIDS.

\section{Conclusion}

In conclusion HIV/AIDS is a problem associated with human development process, thus solutions to the problem should focus on the entire development of the society. Necessary to understand are various cultural conceptions of HIV/AIDS with the view of bringing out salient contesting issues in HIV/AIDS from such cultural conceptions. As pointed out in this paper, there is a great need to harmonize HIV/AIDS research findings even including laboratory-based research from different disciplines to generate a body of local and community specific ideas and knowledge instrumental to positive and pragmatic intervention against HIV/AIDS.

\section{References}

1. Jegede AS. The Impact of HIV/AIDS Pandemics: The state of the Art. A Paper Presented at the American Studies Association Conference in Ghana, May 2002; 23-42.

2. FMOH. HIV/AIDS surveillance Study in Nigeria. Abuja: Federal Ministry of Health. 2003; 17-25. 
3. Osotimehin, B. 1000 Nigerians Die Daily of HIV/AIDS. The Punch, November $28^{\text {th }}, 2003 ; 34$.

4. UNAIDS. Reports on Global AIDs epidemic. Geneva: WHO, July 2005.

5. Ajala AS. Cultural Context of Care and Support for PLWAs in Yoruba Culture. A Paper Presented at the $6^{\text {th }}$ International Conference on Care and Support for PLWAs held in Dakar, Senegal, December 2003; 231-239.

6. Prah KK. Local Culture, Local Memories, and Local Meanings in the Era of Globalization: African Studies Under the Searchlight. Keynote Address, Pan African Anthropological Association $14^{\text {th }}$ Annual Conference. Accra $2^{\text {nd }}-6^{\text {th }}$ August 2004; 1-29.

7. Annan K. UN Secretary-General Cited in UNFPA: Preventing Infection Promoting Reproductive Health: UNFPA's Response to HIV/AIDS, New York: United Nations. 2000; 45-62.

8. Ake C. Political economy of Africa. London: Macmillan, 1978; 93-97.

9. Mufune P. Social Scientific Antecedents of HIV/AIDS Policies in Africa. A Paper Presented at the $30^{\text {th }}$ Anniversary of CODESRIA, in Dakar, December 2003; 76-92.

10. Schoepf B. Women at Risk: Case Studies from Zaire. Herdt G. and S. Linderbaum (eds.) Social Analysis, Theory and Method. Sage London: Beverly Hills. 1998; 271-288.

11. Hunt C. Migrant Labour and Sexually Transmitted Disease: AIDS in Africa. Journal of Health and Social Behavior. 1989; 30:353-373.

12. Ember $\mathrm{M}$ and Ember C. Cultural Anthropology. New York: Applecroft, 1974; 413.

13. Caldwell JP, Caldwell $P$ and Quiggin P. The Social Context of AIDS in SubSaharan Africa. Population and Development Review. 1989; 15:185-234.

14. Philipson T. and Posner R. On the Microeconomics of AIDS in Africa. Population and Development Review. 1995; 21 : 835-848.

15. Aina OI. Women, Culture and Society in Nigeria. In: Sessay, A. and Odebiyi, I.A, Women in Society and Development (eds.). Ibadan: Mathouse, 1995; 72-95.

16. Udegbe B. Gender, Power and Political Leadership in Nigeria. Positive Leadership Monograph Series. 2003; No 8. Lagos: CSSR \& D.Pp: 1-34.

17. Soyibo A. Economic cost of HIV/AIDS. Unpublished paper presented at a workshop on integration of HIV/AIDS into University curricula, University of Ibadan, Nigeria, April 2006; 45-63.

18. Odebiyi A. and Vivekananda F. AIDS in Third World Countries: Africa what are the Alternatives. Scandinavian Journal of Development Alternative. 1991; 10:91-99.

19. Caldwell J. and Caldwell P. The African AIDS Epidemic. Scientific American. 1996; 274:62-68.

20. Johnson BA. The Grassroot Response to HIV/AIDS in Nigeria and Kenya: An Analysis of Community-based Approach for Combating an Epidemic. The Newsletter of the AIDS and Anthropology Research Group. 2003; 15: 3 